\title{
WEWENANG NOTARIS DALAM PEMBUATAN AKTA PERSEROAN TERBATAS YANG MODAL DASARNYA KURANG DARI LIMA PULUH JUTA RUPIAH
}

\author{
Hasan Basri \\ Program Magister Ilmu Hukum \\ Pascasarjana Universitas Islam Malang \\ Email : hasan.bs@gmail.com
}

\begin{abstract}
Abstrak
Penelitian ini bertujuan untuk mengetahui kewenangan Notaris dalam pembuatan Akta PT yang kurang dari Rp. 50.000.000,00 (lima puluh juta rupiah), sebagaimana yang tertuang dalam PP Nomor 29 Tahun 2016 Tentang Perubahan Modal Dasar Perseroan Terbatas bahwa modal dasar pendirian PT diserahkan kepada kesepakatan para pendiri.

Penelitian ini adalah penelitian hukum empiris. Penelitian hukum empiris adalah penelitian hukum yang meneliti data primer. Perolehan data dengan melakukan wawancara kepada narasumber, yaitu akademisi yang menguasai hukum Perseroan Terbatas dan kepada Notaris Hj. Khusnul Hitaminah, SH., MH. yang menjadi objek penelitian.

Besaran modal dasar pendirian Perseroan Terbatas yang diatur dalam ketentuan Pasal 1 ayat (3) PP 292016 ini modal dasar pendirian Perseroan Terbatas menjadi diserahkan pada kesepakatan para pihak/pendiri. Pada prakteknya di Kantor Notaris Hj.Khusnul Hitaminah, SH.,MH. apabila ada Klien yang akan membuat PT dengan modal dasar dibawah Rp.50.000.000,00 (lima puluh juta rupiah), Notaris akan menjelaskan dan mengkonstatir bagaimana keberlangsungan PT tersebut, maka Klien akan lebih memilih wadah usahanya dalm bentuk CV, karena para pendiri hawatir tidak mampu untuk membiayayai operasional PT. Klien yang membuat PT di Kantor Notaris Hj.Khusnul Hitaminah, SH.,MH. modal dasarnya minimal Rp.100.000.000,00 (seratur juta rupiah).
\end{abstract}

Kata kunci: Wewenang Notaris, Perseroan Terbatas, Modal Dasar

\begin{abstract}
This study aims to determine the authority of a Notary Public in the Deed of PT less than Rp. 50,000,000.00 (fifty million rupiah), as stated in PP Number 29 of 2016 concerning Amendment to the Authorized Capital of a Limited Liability Company that the authorized capital for the establishment of a PT is submitted to the agreement of the founders.

This research is an empirical legal research. Empirical legal research is legal research that examines primary data. Obtaining data by conducting interviews with resource persons, namely academics who are in possession of Limited Liability Company law and to Notary Hj. Khusnul Hitaminah, SH., MH. which is the object of research.
\end{abstract}


The authorized capital for the establishment of a Limited Liability Company that is regulated in the provisions of Article 1 paragraph (3) of PP 29 2016, the authorized capital for the establishment of a Limited Liability Company shall be submitted to the agreement of the parties / founders. In practice at the Notary Office of Hj. Khusnul Hitaminah, SH., MH. if there is a Client who will create a PT with an authorized capital of under Rp.50,000,000.00 (fifty million rupiah), the Notary will explain and con-sider how the PT is going to be, the Client will prefer his business container in the form of a $C V$, because the founders are worried unable to finance the operations of PT. Clients who make a PT at the Notary Office Hj.Khusnul Hitaminah, SH., MH. The minimum capital is Rp.100,000,000.00 (one million rupiah).

Keywords: Notary Authority, Limited Liability Company, Authorized Capital

\section{PENDAHULUAN}

Perseroan Terbatas adalah badan hukum. Sebagai badan hukum, perseroan terbatas merupakan subjek hukum dan sebagai subjek hukum perseroan terbatas merupakan pendukung hak dan kewajiban, badan hukum adalah salah satu subjek hukum. Subjek hukum terdiri atas: ${ }^{1}$

a. Orang pribadi (natuurlijk persoon)

b. Badan hukum (rechtspersoon)

Dalam mendirikan sebuah Perseroan Terbatas (PT) dibutuhkan modal agar aktifitas pekerjaan usahanya berjalan dengan baik dan lancar. Oleh karenanya dalam Undang-Undang Nomor 40 Tahun 2007 tentang Perseroan Terbatas ditegaskan bahwa pendirian Perseroan Terbatas agar memiliki modal dasar minimum sebagai syarat pendiriannya. Pemenuhan persyaratan modal minimum dimaksudkan agar pada saat Perseroan Terbatas didirikan setidaknya memiliki modal yakni sebesar modal dasar, modal ditempatkan, dan modal disetor. Modal dasar dalam pendirian perseroan menjadi syarat mutlak yang tidak boleh diabaikan, hal itu untuk membuktikan bahwa perseroan terbatas siap melakukan kegiatan usahanya.

Modal dasar pendirian perseroan ditentukan secara tegas dalam UndangUndang Nomor 40 Tahun 2007 Tentang Perseroan Terbatas Pasal 32 ayat (1) yang menyebutkan: "Modal dasar Perseroan paling sedikit Rp.50.000.000,00 (lima puluh juta rupiah)." Akan tetapi kemudian diterbitkan Peraturan Pemerintah Nomor 29 Tahun 2016 Tentang Perubahan Modal Dasar PT, selanjutnya disebut PP 29/2016. Dalam PP 29/2016 modal dasar pendirian PT diserahkan sepenuhnya pada kesepakatan para pendiri Perseroan Terbatas. Lebih lanjut ketentuan tersebut diatur dalam Pasal 1 Ayat (3) PP 29/2016, menyebutkan: "Besaran modal dasar Perseroan Terbatas sebagaimana dimaksud pada ayat (1) ditentukan berdasarkan kesepakatan para pendiri Perseroan Terbatas".

Kalau kita telaah, diterbitkannya PP 29/2016 ini karena ketentuan dalam Pasal 32 Ayat (3) UUPT 2007 yang memberikan ruang yang berpeluang untuk merubah besaran modal dasar pendirian Rp. 50.000.000 (lima puluh juta rupiah) tersebut melalui Peraturan Pemerintah.

Pada penjelasan bagian umum disebutkan bahwa Peraturan Pemerintah ini dibentuk oleh Pemerintah dalam rangka memberikan ruang kepada para pendiri Hal. 1.

\footnotetext{
${ }^{1}$ Adrian Sutedi, Pintar Hukum Perseroan Terbatas-Cet. 1, Jakarta; Raih Asa Sukses 2015.
} 
Perseroan Terbatas dalam menentukan besaran modal dasar, selain tujuannya untuk memberikan peluang berusaha yang memudahkan pengusaha pemula untuk menumbuhkan banyak perusahaan yang dampaknya adalah meningkatnya investasi yang pada akhirnya pertumbuhan UKM semakin maju pesat. Akan tetapi bagi penulis, diterbitkannya PP 29/2016 ini justru tidak memberikan kepastian hukum mengenai jumlah besaran modal dasar pendirian PT bagi pengusaha pemula.

Adanya perbedaan pengaturan minimal modal dasar PT dalam PP Nomor 29 Tahun 2016 dan Undang-Undang Nomor 40 tahun 2007 memunculkan ragam pendapat. Dikarenakan kedudukan PP yang ditetapkan oleh Presiden berdasarkan Pasal 12 Undang-Undang Nomor 12 Tahun 2011 Tentang Pembentukan Peraturan Perundang-Undangan, menyebutkan bahwa, "Materi muatan Peraturan Pemerintah berisi materi untuk menjalankan Undang-Undang sebagaimana mestinya", selain itu Pemerintah Pemerintah sebagai aturan pelaksana UndangUndang menurut tata urutannya harus berkesesuaian tanpa menyimpangi. ${ }^{2}$ Modal untuk mendirikan perseroan yang diatur sekarang tidak lagi menegaskan minimal modal dasar justeru menyerahkan pada kehendak pesero. Sebagaimana bunyi Pasal 1 ayat (3) Peraturan Pemerintah Nomor 29 Tahun 2016 tentang Perubahan Modal Dasar Perseroan Terbatas berisikan "Besaran modal dasar Perseroan Terbatas sebagaimana dimaksud pada ayat (1) ditentukan berdasarkan kesepakatan para Pendiri Perseroan Terbatas." "Kesepakatan" disini bermakna samar, karena tanpa penjelasan seperti apakah kesepakatan yang dimaksud. Peluang tindak kriminal sangat mungkin terjadi atas dampak dari PP ini. $^{3}$

Selanjutnya, dirasa perlu oleh penulis untuk meneliti bagaimana wewenang Notaris dalam membuat akta pendirian PT, pasca diterbitkannya PP 29/2016 yang memberikan kemudahan dalam menentukan modal dasar pendirian PT bagi pengusaha pemula.

Dalam hal pendirian suatu PT, seorang Notaris memegang kewenangan dalam pembuatan akta pendirian PT, perubahan AD/ART Perusahaan, Pembuatan RUPS. Hal tersebut diatur dalam Pasal 7 ayat (1) UUPT 2007 yang menyebutkan bahwa langkah pendirian PT harus dibuat dihadapan Notaris/secara tertulis (schriftelijk, in writing) berbentuk akta Notariil, bukan dalam bentuk akta dibawah tangan (underhandse akte, private instrument). ${ }^{4}$

Setelah diundangkannya PP 29/2016, ada notaris yang menolak membuat akta pendirian PT dengan modal di bawah Rp. 50.000.000 (lima puluh juta rupiah), dan ada yang telah membuat akta pendirian PT berdasarkan PP 29/2016. Hal ini menarik kemudian untuk dibahas bagaimana wewenang notaris terhadap pembuatan akta dengan modal dasar di bawah Rp. 50.000 .000 (lima puluh juta rupiah).

\section{METODE PENELITIAN}

\footnotetext{
${ }^{2}$ https://vivajusticia.law.ugm.ac.id/2018/02/28/implikasi-yuridis-pasal-1-ayat-3-peraturanpemerintah-nomor-29-tahun-2016-tentang-perubahan-modal-dasar-perseroan-terbatas/, diakses pada tanggal 24 Maret 2019, Pukul 10:20.

3 Ibid, vivajusticia.law.ugm.ac.id/2018/02/28

${ }^{4}$ M. Yahya Harahap, 2015, Hukum Perseroan Terbatas, Sinar Grafika, Jakarta, hlm. 37.
} 
Dalam penelitian ini penulis melakukan penelitian hukum empiris. Menurut Ronny Hanitijo Soemitro Jenis penelitian hukum empiris, ${ }^{5}$ yaitu penelitian hukum yang memperoleh datanya dari data primer atau data yang didapatkan dari responden.

Sedangkan pendekatan penelitian yang dilakukan peneliti yaitu pendekatan kualitatif dalam penelitian hukum empiris. Pendekatan kualitatif yaitu suatu cara analisis hasil penelitian yang menghasilkan data deskriptif analisis, ${ }^{6}$ yaitu data yang dinyatakan oleh responden secara tertulis ataupun lisan serta juga tingkah laku yang nyata, yang diteliti dan dipelajari sebagai suatu yang utuh.

\section{PEMBAHASAN}

Ketentuan Modal Dasar Pendirian Perseroan Terbatas Bagi Pengusaha Pemula Pasca Diterbitkannya PP No. 29 Tahun 2016 Tentang Perubahan Modal Dasar Pendirian Perseroan Terbatas Dikaitkan Dengan Kemampuan PT Dalam Menjalankan Kegiatan Usahanya

Di dalam Pasal 32 ayat (3) Undang-Undang Nomor 40 Tahun 2007 Tentang Perseroan Terbatas diatur terkait perubahan modal dasar Perseroan ditetapkan dengan Peraturan Pemerintah. Pasal inilah yang menjadi dasar hukum bagi Peraturan Pemerintah Nomor 29 Tahun 2016 tentang Perubahan Modal Dasar Perseroan Terbatas (PP 29/2016). Dengan dikeluarkannya PP ini maka Peraturan Pemerintah Nomor 7 Tahun 2016 tentang Perubahan Modal Dasar Perseroan Terbatas (PP 7/2016) yang dikeluarkan pada tahun yang sama dicabut dan dinyatakan tidak berlaku.

Pada bagian penjelasan dinyatakan bahwa tujuan diterbitkannya peraturan pemerintah ini adalah agar pengusaha pemula mudah mendirikan usaha dan diharapkan naiknya angka investasi di Indonesia sehingga UKM bisa bertumbuh. Pada PP 29/2016 terjadi perubahan yang cukup besar terhadap ketentuan yang ditetapkan dalam UUPT dan juga PP sebelumnya. Hal ini menjadi isu utama dalam penelitian tesis pada PP ini.

Pasal 32 ayat (1) UUPT menetapkan modal dasar PT paling sedikit Rp. 50.000.000,00- (lima puluh juta rupiah). Dalam PP nomor $7 / 2016^{7}$ juga masih menetapkan modal dasar PT paling sedikit Rp. 50.000.000,00 (lima puluh juta rupiah) namun terdapat pengecualian pada Pasal 1 ayat (2) nya dimana apabila salah satu atau seluruh pihak pendiri PT memiliki kekayaan bersih sesuai kriteria UMKM, maka modal dasarnya tergantung kesepakatan para pesero PT.

Peraturan Pemerintah Nomor 29 Tahun 2016 kemudian melakukan perubahan yang lebih jauh yang mana besaran modal dasar PT tidak lagi ditentukan minimalnya akan tetapi diserahkan sepenuhnya kepada pendiri PT. Jika pada PP 7/2016 hal ini hanya dapat dilakukan oleh UMKM, maka pada PP 29/2016, norma ini menjadi berlaku bagi seluruh PT. Dengan demikian, terjadi penyimpangan, PP telah menyimpangi ketentuan yang telah ditetapkan dalam UU PT yang menetapkan ketentuan minimal modal dasar PT.

\footnotetext{
${ }^{5}$ Ronny Hanitijo Soemitro, dalam bukunya Mukti Fajar \& Yulianto Achmad, 2010, Dualisme Penelitian Hukum Normatif \& Empiris, Yogyakarta, Pustaka Pelajar, hlm 154.

${ }^{6}$ Mukti Fajar \& Yulianto Achmad, 2010, Dualisme Penelitian Hukum Normatif \& Empiris, Yogyakarta, Pustaka Pelajar, hlm. 192.

${ }^{7}$ PP Nomor 7 Tahun 2016
} 
Padahal PP disini sebagai pelaksana dari muatan Undang-Undang, tidak boleh kemudian PP menyimpangi muatan materi Undang-Undang. Jika memang harus merubah ketentuan modal dasar karena kebutuhan untuk meningkatkan investasi ataupun kemudahan berusaha, konsekuensi pemerintah harusnya mengambil jalan untuk merubah UU PT nya, kalau hal ini dirasa akan menghambat jalannya ekonomi dan investasi karena proses perubahan undangundang harus melibatkan lagislatif, maka pemerintah bisa mengeluarkan Perpu jika kondisinya sangat mendesak dan urgen.

Atas dasar hal ini, harus dipertimbangkan benar-benar apakah pengahpusan besaran minimum modal dasar PT yang diatur dalam PP 29/2016 sudah tepat dan tidak melanggar asas kehati-hatian atau perlindungan terhadap masyarakat. Penulis memandang bahwa ketentuan modal dasar pendirian PT harus tetap ada demi perlindungan terhadap masyarakat. Para pemangku kepentingan dapat mendiskusikan jumlah besaran modal dasar PT. Sementara itu, tetap dibuka kemungkinan bagi sektor usaha tertentu untuk melakukan pengecualian terhadap ketentuan ini dengan mengatur batasan modal minimum jika diperlukan.

\section{Wewenang Notaris dalam Pembuatan Akta Pendirian Perseroan Terbatas Pasca Diterbitkannya PP/29 Tahun 2016 Tentang Perubahan Modal Dasar Perseroan Terbatas}

Wewenang Notaris dalam pembuatan akta PT pasca diterbitkannya PP Nomor 29 Tahun 2016 tidak mengalami perubahan, artinya wewenang Notaris sama saja dalam membuat akta PT baik dengan modal dasar minimal Rp.50.000.000,00 (lima puluh juta rupiah) ataupun dengan modal dasar berdasarkan kesepakatan para pendiri PT yang diatur dalam Pasal 1 ayat (3) PP 29/2016. Akan tetapi, sejak PP 29/2016 diterbitkan, di Kantor Notaris $\mathrm{Hj}$. Khusnul Hitaminah, SH., MH. belum pernah membuat akta pendirian PT dibawah ketentuan yang diatur oleh Undang-Undang Perseroan Terbatas yakni Rp.50.000.000,00 (lima puluh juta rupiah), karena para pihak/pesero yang membuat akta PT di Notaris $\mathrm{Hj}$. Khusnul Hitaminah, SH., MH. sendiri menyertakan modal dasar minimum sebesar Rp.500.000.000,00 (lima ratus juta rupiah).

Notaris memandang, perubahan yang dilakukan oleh PP 29/2016 ini menyimpangi modal dasar yang diatur dalam UUPT, seharusnya ketentuan modal dasar itu tetap mengacu pada Undang Undang Nomor 40 Tahun 2007 Tentang Perseroan Terbatas yang mengatur besaran modal minimal Rp. 50.000.000,00 (lima puluh juta rupiah). Penulis juga beranggapan harusnya dinaikkan menjadi minimal Rp.100.000.000,00 (seratus juta rupiah), untuk mengantisipasi laju inflasi yang semakin besar.

Dalam membuat akta PT berdasarkan PP Nomor 29 Tahun 2016, dalam hal ini merupakan kewenangan Notaris adalah mengkonstatir hal-hal yang ingin dituangkan oleh para pihak kedalam akta PT, ini dimaksudkan supaya Klien mengikuti ketetntuan Peraturan Perundang-Undangan, disamping itu kehendak para pesero bisa terakomodir dengan baik dan benar. Dari itu, tanggung jawab Notaris bertanggung jawab meliputi pemembuatan akta otentik dan juga berkewajiban menyosialisasikan hukum khususnyaa terkait pendirian PT dengan kesepakatan modal dasar kecil, seorang Notaris perlu memberikan pemahaman 
kepada klien bagaimana pelaksanaan usaha PT dengan modal kecil kedepannya. Dalam mendirikan PT berdasarkan PP 29/2016, ada Notaris yang menolak membuat akta PT dengan modal dasar dibawah Rp. 50.000.000,00 (lima puluh juta rupiah) dengan alasan bahwa UU kedudukannya lebih tinggi sehingga dalam menlankan wewenangnya memilih untuk selalu tunduk pada ketentuan undangundang.

Seperti halnya di Kantor Notaris Hj. Khusnul Hitaminah, SH., MH. ketika ada klien untuk mendirikan usaha berbadan hukum dengan berdasar pada PP 29/2016, maka klien memilih untuk buat CV (Commanditare Vennostchap) karena hawatir tidak mampu untuk menjalankan usahanya, karena menilai dengan modal dibawah Rp. 50.000.000,00 (lima puluh juta rupiah) akan kesulitan menerima tender-tender besar. Dan klien yang membuat PT di Kantor Notaris $\mathrm{Hj}$. Khusnul Hitaminah, SH., MH. modal dasarnya minimal Rp. 100.000.000,00 (seratus juta rupiah), lebih dari kecil dari itu belum ada. Karena memang kalau sudah usaha dalam bentuk Perseroan Terbatas ini skalanya besar yang mana sudah dipastikan proyek dan tender besar membutuhkan biaya yang besar pula.

Memang kalau dilihat dari sisi tujuan diterbitkannya PP 29/2016 ini yakni untuk memberikan kemudahan dalam berusaha dan meningkatkan pertumbuhan investasi, sehingga disitu akan banyak perkembangan usaha yang berwadah badan hukum. Akan tetapi, ketentuan modal dasar yang diatur dalam PP 29/2016 ini menyimpangi ketentuan modal dasar dalam Undang-Undang Nomor 40 tahun 2007 Tentang Perseroan Terbatas yang ditentukan minimal Rp. 50.000.000,00 (lima puluh juta rupiah).

Jadi kewenangan ini tidak ada perubahan pasca diterbitkannya PP 29/2016, hanya saja di Kantor Notaris Hj. Khusnul Hitaminah, SH., MH. belum pernah mebuat akta PT berdasarkan kesepakatan para pihak seperti yang diatur dalam PP 29/2016

\section{PENUTUP}

Pasal 32 ayat (3) menjadi pintu masuk diterbitkannya Peraturan Pemerintah Nomor 29 Tahun 2016 Tentang Perubahan Modal Dasar Perseroan Terbatas, yang mana sebelumnya diterbitkan PP di tahun yang sama yakni PP Nomor 7 Tahun 2016 Tentang Perubahan Modal Dasar Perseroan Terbatas, dalam PP 7/2016 masih menetapkan modal dasar PT sedikitnya Rp. 50.000.000,00 (lima puluh juta rupiah), kemudian diganti dengan PP 29/2016 yang melakukan perubahan cukup jauh dengan menghapus ketentuan modal dasar PT menjadi diserahkan kepada kesepakatan pendiri PT. Pada kitab Undang-Undang Hukum Dagang tidak mengatur ketentuan modal dasar PT, yang terjadi saat itu banya PT palsu berdiri, kemudian diterbitkan Undang Undang Nomor 1 Tahun 1995 Tentang Perseroan Terbatas yang mulai mengatur mengenai modal dasar PT sebesar Rp. 20.000.000,00 (dua puluh juta rupiah) pada Pasal 25 ayat (1). Mengikuti perkembangan ekonomi yang kian dinamis, akhirnya diterbitkan kembali Undang-Undang Nomor 40 Tahun 2007 Tentang Perseroan Terbatas, untuk memenuhi kepastian hukum dan tuntutan pengembangan usaha yang berprinsip pengelolaan perusahaan yang baik. Dari itu, perlu dipertimbangkan oleh Pemerintah terhadap penghapusan minimum modal dasar PT yang diatur dalam PP 29/2016 ini harus benar benar sesuai dengan kebutuhan dan juga memberikan perlindungan bagi masyarakat. 
Wewenang Notaris tidak ada perubahan pasca diterbitkannya PP 29/2016, artinya wewenang notaris sama saja pasca diterbitkannya PP 29/2016 maupun sebelumnya. Hanya saja di Kantor Notaris Hj. Khusnul Hitaminah, SH., MH. sejak diterbitkannya PP 29/2016 ini hingga sekarang belum ada yang membuat akta pendirian PT berdasarkan PP 29/2016 ini, minimal klien yang mebuat akta pendirian Perseroan Terbatas di Kantor Notaris $\mathrm{Hj}$. Khusnul Hitaminah, SH., MH adalah sebesar Rp. 500.000.000,00 (lima ratur juta rupiah), karena PT merupakan usaha skala besar yang menangani tender besar pula. Adapun manakala ada klien yang mau mendirikan usaha dengan modal dibawah Rp.50.000.000,00 (lima puluh juta rupiah), klien tersebut memilih bentuk usaha dalam bentuk $\mathrm{CV}$, karena khawatir tidak mampu melaksanakan kegiatan usahanya. Notaris berpandangan kalau PP Nomor 29 Tahun 2016 ini menyimpangi ketentuan modal dasar PT yang diatur dalam Undang-undang Nomor 40 Tahun 2007 Tentang Perseroan Terbatas, dan Notaris $\mathrm{Hj}$. Khusnul Hitaminah, SH., MH. lebih memilih tunduk pada undang-undang untuk lebih kehati-hatiannya khususnya dalam pembuatan akta pendirian Perseroan Terbatas ini.

Dalam hal pembuatan akta PT, Notaris sebaiknya memberikan penyuluhan hukum, akan dampak positif dan negatifnya apabila ada klien yang ingin membuat akta PT berdasarkan PP 29/2016.

\section{DAFTAR PUSTAKA}

\section{Buku}

Adrian Sutedi, Pintar Hukum Perseroan Terbatas, 2015. Raih Asa Sukes, Jakarta. Habib Adji, Penafsiran Tematik Hukum Notaris Indonesia, 2015. PT Refika Aditama, Bandung.

Munir Fuady, Hukum Perseroan Terbatas Paradigma Baru, PT. Citra Aditya Bakti, Bandung.

M. Yahya Harahap, Hukum Perseroan Terbatas, 2015, Sinar Grafika, Jakarta.

Nur Dewata, Mukti Fajar, dan Achmad, Yulianto, Dualisme Penelitian Hukum Normatif \& Empiris, 2017, Pustaka Pelajar, Yogyakarta.

Oemar Moechtar, Dasar-Dasar Teknik Pembuatan Akta, 2017, Airlangga University Press, Surabaya.

Peter Mahmud Marzuki, Penelitian Hukum, 2016, Prenadamedia Group, Jakarta.

Peter Mahmud Marzuki, Pengantar Ilmu Hukum, 2012, Prenadamedia Group, Jakarta.

Soerjono Soekanto, Penelitian Hukum Normatif Suatu Tinjauan Singkat, 2015,. PT. Grafindo Persada, Jakarta.

\section{Undang-Undang}

Undang-Undang Perseroan Terbatas (UU RI No. 40 Th. 2007) 2009, Sinar Grafika, Jakarta.

Undang-Undnag Nomor 40 Tahun 2007 tentang Perseroan Terbatas.

Peraturan Pemerintah Nomor 29 Tahun 2016 Tentang Perubahan Modal Dasar Perseroan Terbatas. 